\title{
A Study On The Usability of Moodle and Blackboard - Saudi Students Perspectives
}

https://doi.org/10.3991/ijim.v14i10.14381

\author{
Aseel Alghafis ${ }^{(\varpi)}$, Atheer Alrasheed, Amal Abdulghany \\ Qassim University, Buraydah, Saudi Arabia \\ Aseel . algha fees agmail . com
}

\begin{abstract}
Nowadays, e-learning management systems are used in many universities around the world. In Saudi Arabia, universities use several systems such as Moodle and Blackboard. However, only little empirical research has been conducted on Saudi students' preference for such systems. This study compared the usability of Moodle and Blackboard systems among Saudi university students. Specifically, three comparison metrics have been considered: user interface, download and upload service and materials organization. The results showed that the students preferred Moodle and believed that it is more usable than Blackboard in all studied metrics.
\end{abstract}

Keywords - E-learning, Learning Management Systems, Usability

\section{$1 \quad$ Background}

The Learning Management System (LMS) is used as a tool to provide students with different resources (handouts, links, software) [1]. Two of the most popular LMS are Blackboard and Moodle. These two systems consist of various tools such as content management tools, communication tools, assignment submission tools and student evaluation tools [2].

Developers of LMS's mostly consider several criteria. One of the main criteria is usability [3]. Usability refers to "the extent to which a product can be used by specified users to achieve specified goals with effectiveness, efficiency a satisfaction in a specified context of the user." [4].

E-learning is defined in [5] as earning of knowledge and skill at local and wide area networks using electronic technologies. Online learning has advantages over traditional face-to-face education such as time-saving and labor intensiveness [6].

A variety of e-learning models are available. The first model is synchronous training (at the same time) that provides the freedom to the students to discuss with the mentor and also among themselves via the e-classroom with the use/help of tools such as the videoconference and/or chat rooms [7]. The second is asynchronous (not at the same time), this type allows the students to discuss with the instructors as well as among themselves over the internet on his / her own pace without live interaction with the instructor [7]. The last type is blended learning, so the course materials are shared between the traditional learning method and the e-learning method [5]. 
Learning management systems (LMS) is software that design to manage users learning activities, taking into consideration the features that will make this possible [8]. Authors in [9] indicated that a learning management system (LMS) is a software application created to plan, administrate, report, track, and deliver education courses. Learning management systems have been a worldwide phenomenon in higher education. ELearning management systems advancement in technology has been revolutionized the approach of educators and teach students to learn. One example of this revolution is the development of learning management systems (LMS) that ease teaching and learning outside the physical classroom [10].

Two common LMS's are available, Blackboard and Moodle. Blackboard Learning System is a web-based learning management system designed for students and faculty to allow them to participate in classes delivered online. Also, Blackboard is a comprehensive and flexible E-Learning software platform that provides a complete course management system [11]. Moodle stands for Modular Object-Oriented Dynamic Learning Environment [3]. It is a free and open-source platform that educators use it to create efficient online learning sites' [12].

The open-source community has been active in creating alternative learning management system choices that are free of licensing costs [3].

Much research has been conducted on studying the general features of Blackboard and Moodle([4], [3], [2],[1],[5], [6], [7],[8],[9]). In Saudi Arabia, only little empirical research has been done on these systems. The authors in [2] studied the acceptance of Blackboard within Saudi students. In [8], the authors evaluated the usability and accessibility of Blackboard. The study was conducted at King Saud University.

This paper compares the usability of two LMS's, Blackboard and Moodle, based on students' perspectives. These two systems were selected as most Saudi universities use either Blackboard or Moodle systems.

\section{Survey Design}

This study is to answer the following research question: Which system is more usable for Saudi students: Blackboard or Moodle?

The study was conducted using an online questionnaire. The methodology followed to design and analyze the questionnaire is based on [10] and [11].

The participants are students from Prince Sultan University. In this university, Blackboard is used as an LMS. The participant was chosen based on experience, i.e. the subjects are students who have used the Moodle system before.

To design the questionnaire questions, the metrics of usability that are compared have been identified first. These metrics are:

1. User interface, which includes interactivity, color and font size of the interface [1].

2. Download and upload the files, which includes speed, size and types of files " materials" that can be download/uploaded [1].

3. Organization of learning materials, which include structure style of materials, ease of access to subheadings and clarity arrangement of each course [2]. 
These metrics were selected because they are the most used services by students [2]. The questionnaire of the study comprises 2 sections. The first section describes the participants' demographic information and consists of 5 questions: age, gender, prior experience with e-learning management systems, education level, and field of study. The second section includes specific questions about the usability of Blackboard and Moodle based on the metrics identified earlier. The Likert scale was used to rate the responses on a scale of 1 to 5 as shown below.

1. Strongly disagree

2. Disagree

3. Neither agree nor disagree

4. Agree

5. Strongly agree

The survey questions are shown in Table 1.

Table 1. Survey Questions

\begin{tabular}{|l|l|}
\hline \multicolumn{1}{|c|}{ Criteria } & \multicolumn{1}{c|}{ Item } \\
\hline Interface & Blackboard more interactive than Moodle \\
\cline { 2 - 2 } & Blackboard has better color interface than Moodle \\
\cline { 2 - 2 } & Font in Blackboard is better customized than Moodle \\
\hline $\begin{array}{l}\text { Organization of } \\
\text { materials }\end{array}$ & Blackboard has better structure of materials than Moodle \\
\cline { 2 - 2 } & \begin{tabular}{l} 
In Blackboard can be access to subheadings easier than Moodle \\
\cline { 2 - 2 } $\begin{array}{l}\text { In Blackboard, the arrangement of each course can be shown in a clear manner } \\
\text { than Moodle }\end{array}$
\end{tabular} \\
\hline service of files & $\begin{array}{l}\text { Blackboard has the ability to download and upload the files faster than Moodle } \\
\text { By using Blackboard can upload larger size of files than Moodle }\end{array}$ \\
\cline { 2 - 2 } & $\begin{array}{l}\text { Blackboard enables to upload more types of materials, books , papers, images " } \\
\text { better than Moodle }\end{array}$ \\
\hline
\end{tabular}

\section{Survey Results}

Twenty-five students responded to the questionnaire. All of them have experience in both Blackboard and Moodle for at least one year. All of them are bachelor's degree students from different majors including: engineering, business, administration, law and computer science. The survey results are shown in Table 2, 3 and 4.

As shown in Table 2 shows the comparison between Blackboard and Moodle in terms of the interface. This metric includes different criteria like interaction, interface color so that they are comfortable for the eye and not bright, and the appropriate font size. 
Table 2. The results of the interface metric

\begin{tabular}{|l|c|c|c|c|c|}
\hline \multicolumn{1}{|c|}{ Interface metric questions } & $\begin{array}{l}\text { Strongly } \\
\text { disagree }\end{array}$ & Disagree & $\begin{array}{c}\text { Neither agree } \\
\text { nor agree }\end{array}$ & Agree & $\begin{array}{c}\text { Strongly } \\
\text { agree }\end{array}$ \\
\hline Blackboard more interactive than Moodle & $28 \%$ & $36 \%$ & $20 \%$ & $16 \%$ & $0.0 \%$ \\
\hline $\begin{array}{l}\text { Blackboard has better color interface than Moo- } \\
\text { dle }\end{array}$ & $28 \%$ & $44 \%$ & $20 \%$ & $0.0 \%$ & $8 \%$ \\
\hline $\begin{array}{l}\text { Font customization in Blackboard better than } \\
\text { Moodle }\end{array}$ & $32 \%$ & $28 \%$ & $24 \%$ & $16 \%$ & $0.0 \%$ \\
\hline
\end{tabular}

The table above shows that $64 \%$ of the respondents agree that Moodle is more interactive than Blackboard, $72 \%$ of the respondents agree that Moodle has a better interface in terms of using colors, and that $60 \%$ of the respondent agree that Moodle is better in terms of the font as well. In summary, the results showed that Moodle outperforms Blackboard in terms of interface design.

Table 3 shows the comparison between Blackboard and Moodle in terms of the download and upload service. This metric includes different criteria such as the speed of downloading and uploading files, the maximum size of the files that can be downloading and uploading, and the types of materials that the system can support for downloading and uploading.

Table 3. The results of downloading and uploading metric

\begin{tabular}{|c|c|c|c|c|c|}
\hline $\begin{array}{c}\text { Downloading and uploading the files metric } \\
\text { questions }\end{array}$ & $\begin{array}{l}\text { Strongly } \\
\text { disagree }\end{array}$ & Disagree & $\begin{array}{c}\text { Neither agree } \\
\text { nor agree }\end{array}$ & Agree & $\begin{array}{c}\text { Strongly } \\
\text { agree }\end{array}$ \\
\hline $\begin{array}{l}\text { Blackboard has the ability to download and upload } \\
\text { the files faster than Moodle }\end{array}$ & $24 \%$ & $36 \%$ & $28 \%$ & $8 \%$ & $4 \%$ \\
\hline $\begin{array}{l}\text { By using Blackboard can be upload bigger size of } \\
\text { files than Moodle }\end{array}$ & $8 \%$ & $64 \%$ & $20 \%$ & $8 \%$ & $0.0 \%$ \\
\hline $\begin{array}{l}\text { Blackboard enables to upload more types of material } \\
\text { better than Moodle }\end{array}$ & $20 \%$ & $48 \%$ & $20 \%$ & $12 \%$ & $0.0 \%$ \\
\hline
\end{tabular}

The table above $60 \%$ of the respondents agree that Moodle is faster than of than Blackboard in terms of downloading and uploading file, $72 \%$ of the respondents agree that Moodle allows uploading unlimited size of files which is better than Blackboard, and $68 \%$ of the respondents agree that Moodle enable more types of uploaded file as compared to Blackboard. In summary, students believe that Moodle is better than Blackboard in terms of downloading and uploading files.

Table 4 shows the comparison between the two systems in terms of materials organization metric. This includes the structure of materials, the ease of accessing sub-headings and the clarity in the arrangement of courses. 
Table 4. The results of the materials organization metric

\begin{tabular}{|l|c|c|c|c|c|}
\hline \multicolumn{1}{|c|}{ Organization of materials metric questions } & $\begin{array}{c}\text { Strongly } \\
\text { disagree }\end{array}$ & $\begin{array}{c}\text { Dis- } \\
\text { agree }\end{array}$ & $\begin{array}{c}\text { Neither agree } \\
\text { nor agree }\end{array}$ & $\begin{array}{c}\text { Agree } \\
\text { Strongly } \\
\text { agree }\end{array}$ \\
\hline $\begin{array}{l}\text { Blackboard has a better structure of materials than } \\
\text { Moodle }\end{array}$ & $28 \%$ & $52 \%$ & $12 \%$ & $0 \%$ & $8 \%$ \\
\hline $\begin{array}{l}\text { In Blackboard can be access to subheadings easier } \\
\text { than Moodle }\end{array}$ & $20 \%$ & $52 \%$ & $24 \%$ & $4 \%$ & $0.0 \%$ \\
\hline $\begin{array}{l}\text { In Blackboard, the arrangement of each course can be } \\
\text { shown in a clear manner than Moodle }\end{array}$ & $20 \%$ & $60 \%$ & $9 \%$ & $3 \%$ & $8 \%$ \\
\hline
\end{tabular}

The table above $80 \%$ of the respondents agree that Moodle provides has a better way of structuring materials as compared to Blackboard, $72 \%$ of the respondents agree that it is easier in Moodle to access subheadings, and $80 \%$ of the respondents agree that Moodle provides a better arrangement of the course items. In summary, the results showed that Moodle is also better than Blackboard in terms of the organization of files.

Fig. 1 shows an a summary of the results shown in Table 2, 3 and 5 in a graphical form.
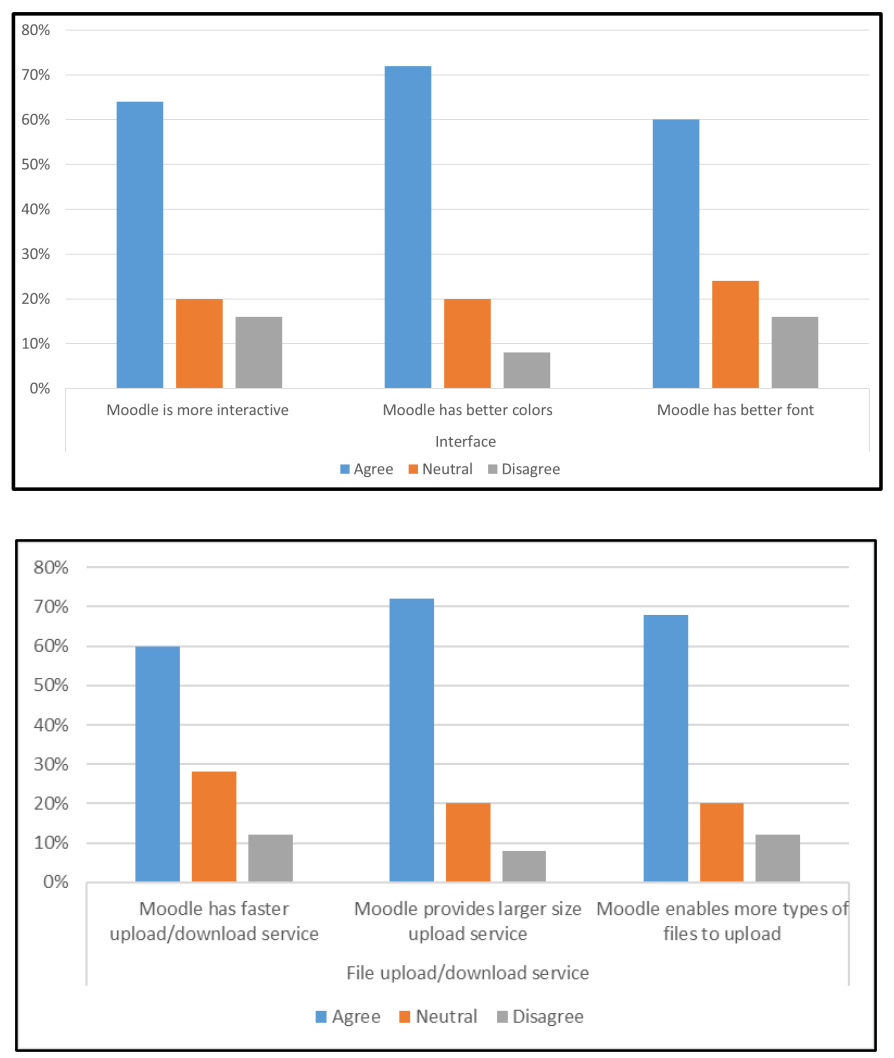


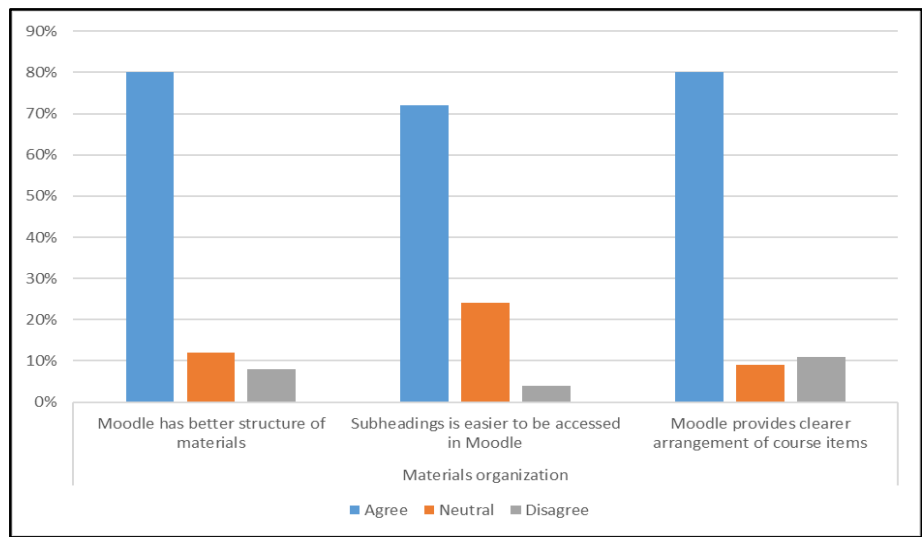

Fig. 1. Students prefer Moodle over Blackboard in all usability metrics

In a nutshell, students prefer Moodele over Blackboard and believe that the former is more usable than the latter.

\section{Conclusion}

The goal of this study was to compare the usability of two competing learning management systems in Saudi Arabia, Moodle and Blackboard. Using the survey method, we examined three usability metrics which are user interface, downloading and uploading service and materials organization. The samples were twenty-five Saudi university students. Results showed the students preferred the Moodle learning management system over Blackboard in terms of usability. In the future, we plan to replicate this study with a larger sample of students from other different Saudi universities. We also plan to include more usability metrics in the comparison and collect some qualitative data from the students.

\section{$5 \quad$ References}

[1] D. Bremer and R. Bryant, "A Comparison of two learning management Sys-tems: Moodle vs Blackboard," in Proceedings of the 18th Annual Conference of the National Advisory Committee on Computing Qualifications, 2005, pp. 135-139.

[2] S. Binyamin, M. Rutter, and S. Smith, "The Students' Acceptance of Learn-ing Management Systems in Saudi Arabia: A Case Study of King Abdulaziz Uni-versity," Valencia, Spain, International Academy of Technology, Education and Development (IATED), 2017. https://doi.org/10.21125/inted.2017.2205

[3] M. Machado and E. Tao, "Blackboard vs. Moodle: Comparing user experi-ence of learning management systems," in Frontiers in education conference-global engineering: knowledge without borders, opportunities without passports, 2007. FIE'07. 37th annual, 2007, pp. S4J7-S4J-12: IEEE. https://doi.org/10.1109/fie.2007.4417910 
[4] G. Kakasevski, M. Mihajlov, S. Arsenovski, and S. Chungurski, "Evaluating usability in learning management system moodle," in ITI, 2008, vol. 2008, p. 30th. https://doi.org/10. $\underline{1109 / \text { iti.2008.4588480 }}$

[5] N. Cavus and T. Zabadi, "A comparison of open source learning manage-ment systems," Procedia-Social and Behavioral Sciences, vol. 143, pp. 521-526, 2014. https://doi.org/10. 1016/j.sbspro.2014.07.430

[6] F. Martin, "Blackboard as the learning management system of a computer literacy course," Journal of Online Learning and Teaching, vol. 4, no. 2, pp. 138-145, 2008.

[7] P. Subramanian, N. Zainuddin, S. Alatawi, T. Javabdeh, and A. Hussin, "A study of Comparison between Moodle and Blackboard based on Case Studies for better LMS," Journal of Information Systems Research and Innovation, vol. 6, pp. 26-32, 2014.

[8] U. T. Alturki and A. Aldraiweesh, "Evaluating the Usability and Accessibility of LMS" Blackboard" at King Saud University," Contemporary Issues in Education Research, vol. 9, no. 1, pp. 33-44, 2016. https://doi.org/10.19030/cier.v9i1.9548

[9] A. Carvalho, N. Areal, and J. Silva, "Students' perceptions of Blackboard and Moodle in a Portuguese university," vol. 42, no. 5, pp. 824-841, 2011. https://doi.org/10.1111/j.1467$\underline{8535.2010 .01097 . \mathrm{x}}$

[10] A. Fink, The survey handbook. Sage, 2003.

[11] J. W. Creswell, "Research design," Qualitative and Quantitative Approach. Thousand Oaks: SagePublications, 1996.

[12] Budiman, R. (2013). Utilizing Skype for providing learning support for In-donesian distance learning students: A lesson learned. Procedia - Social and Behavioral Sciences, 83: 5-10. https://doi.org/10.1016/j.sbspro.2013.06.002

[13] Chandrasena Premawardhena, N., ICT in the foreign language classroom in Sri Lanka: A journey through a decade. 10th World Conference on Computers in Education (WCCE 2013), Nicolaus Copernicus University, July 2-5 2013, Torun, Poland.pp 223-224

[14] Chandrasena. Premawardhena, N. (2012). Introducing Computer-Aided Language Learning to Sri Lankan Schools: Challenges and Perspectives. 15th International Conference on Interactive Collaborative Learning and 41st International Conference on Engineering Pedagogy (ICL \& IGIP), Villach, Austria. https://doi.org/10.1109/icl.2012.6402118

\section{Authors}

Aseel Alghafis is a lecturer in Department of Information Technology, Community College, Saudi Arabia. She holds a Master's Degree in Informatics. She was graduated from the Computer Science Department, College of Computer, Qassim University, Saudi Arabia.

Atheer Alrasheed is a lecturer in Department of Information Technology, Community College, Saudi Arabia. She holds a Master's Degree in Informatics. She was graduated from the Computer Science Department, College of Computer, Qassim University, Saudi Arabia.

Amal Abdulghany is an assistant professor in the Information Technology Department, College of Computer, Qassim University, Saudi Arabia.

Article submitted 2020-03-24. Resubmitted 2020-05-03. Final acceptance 2020-05-05. Final version published as submitted by the authors. 